\title{
Winchell, Walford, or Malclès?
}

BY FRANCES SEAHOLM

"WINCHELl" is, of course, Guide to Reference Books, the seventh and current edition of which is edited by Constance M. Winchell. "Walford" is Arthur J. Walford's Guide to Reference Material, similar to Winchell but slanted for Great Britain. And "Malclès" refers to LouiseNoëlle Malclès's three-volume Les Sources du travail bibliographique, which is in a general way the French counterpart to the other two works.

Winchell, Walford, or Malclès?

Large libraries need not make a choice; they can afford to have them all on hand. The smaller library picks Winchell first, Walford next, and Malclès last or not at all (for reasons of cost and emphasis).

But does any one of them do all that a general guide to reference materials could and should? What are the strengths and weaknesses of each? As a step toward evaluation, a comparative study was made of the three works.

Indexing is vitally important to such books as these. All had scatterings of misprints, misspellings, and in some cases incorrect page numbers. Apart from these common faults, the differences, in an area in which there should be standardized quality, are startling.

Winchell's index is the most satisfactory of the three. She usually has both author and title entries, and subject entries are scattered throughout, as they are in all three guides. Walford sometimes gives both author and title entries, but he is equally likely to give just author entries. Occasionally where an author entry would be expected, he will have a title entry instead.

Both of these books follow the author entry in the index with the title of each work in the book and its page number.
Mrs. Seaholm resides in Plainfield, Illinois.

This is never done by Malclès, and it is this omission which makes her index the least satisfactory. She gives the name of the author and lists the numbers of the pages on which his works appear. (Generally if there is an author only author entry is given.) It is then necessary to check each page listed to discover which bears the desired work. With prolific authors there may be as many as eight or ten pages to glance over. And should the author's name be a common one and the Christian names not known, the number of pages that require checking may easily exceed the patience of the searcher.

Another inconvenience presented by Malclès is the number of indexes. (Winchell, too, suffers from this problem when her supplements are considered.) Malclès has three indexes, one at the end of each complete volume. Because the volumes were issued at different times, this is unavoidable. However, the last index might well have included page numbers in previous volumes for works. appearing not only in Volume III but also in previous volumes.

In the standard library custom, all three of these works index Mac and Mc together alphabetically-but Malclès actually spells $\mathrm{Mc}$ as $\mathrm{M}-\mathrm{a}-\mathrm{c}$ !

Except for occasional comments, usually on additional sources, Walford has no introductory material other than the introduction to the book. The other two works contain such material at the beginnings of chapters, at subject classification divisions, etc. Malclès devotes 11.15 per cent of Les Sources to introductory material, 192.62 of her 1772 pages. Winchell 
TABLE 1

\begin{tabular}{|c|c|c|c|c|c|}
\hline WALFORD & \multirow[b]{2}{*}{ Per cent } & \multicolumn{2}{|c|}{ WINCHELL } & \multicolumn{2}{|c|}{ MALCLÈs } \\
\hline & & & Per cent & Volume & Per cent \\
\hline 0 Generalities & 12.55 & A-G & 21.98 & Vol. I & 22.62 \\
\hline 1 Philosophy \& psychology & 1.67 & H-J & 1.17 & $\mathrm{II}^{2}$ Ch. 17 & 3.30 \\
\hline 2 Religion & 4.18 & K & 5.06 & $\mathrm{II}^{1} \mathrm{Ch} .13$ & 3.05 \\
\hline 3 Social sciences & 13.60 & $\mathrm{~L}$ & 13.23 & $\mathrm{II}^{2} \mathrm{Ch} .16$ & 5.18 \\
\hline 4\&8 Languages \& literature & 16.11 & M-R & 21.21 & $\mathrm{II}^{1}$ Ch. $3,8-12$ & 13.74 \\
\hline 5\&6 Science \& technology & 3.77 & & & III Ch. 1,2 & 1.88 \\
\hline $\begin{array}{c}5 \text { Mathematics \& natural } \\
\text { sciences }\end{array}$ & 6.07 & $\mathbf{N}$ & 8.11 & $\begin{array}{l}\text { II }^{1} \text { Ch. 2, 5-77; } \\
\text { III Ch. 3-11 }\end{array}$ & 32.60 \\
\hline $\begin{array}{l}6 \text { Applied sciences } \\
7 \text { The arts }\end{array}$ & $\begin{array}{r}15.06 \\
8.79\end{array}$ & $\begin{array}{l}\mathbf{P} \\
\mathbf{Q}\end{array}$ & $\begin{array}{l}6.64 \\
5.64\end{array}$ & $\begin{array}{l}\text { III Ch. 12, } 13 \\
\text { II }^{2} \text { Ch. } 15\end{array}$ & $\begin{array}{l}6.16 \\
3.24\end{array}$ \\
\hline 9 Geography, Biography, & & & & & \\
\hline 91 Geography, exploration & & & & & \\
\hline $\begin{array}{l}\text { \& travel } \\
92 \text { Biography }\end{array}$ & 3.35 & S-T & $\begin{array}{l}3.31 \\
5.64\end{array}$ & $\mathrm{II}^{2} \mathrm{Ch} .14$ & 1.43 \\
\hline $\begin{array}{l}92 \text { Biography : : } \\
93 \text { History }\end{array}$ & $\begin{array}{l}5.02 \\
9.83\end{array}$ & V & $\begin{array}{l}3.04 \\
7.98\end{array}$ & $\mathrm{II}^{1} \mathrm{Ch} .4$ & \\
\hline
\end{tabular}

uses 23.6 pages, 4.6 per cent of her total of 512 , for such work.

Malclès and Winchell differ considerably in type as well as amount of this material. Malclès emphasizes the scholarly and Winchell the practical, library-oriented point of view. For example, Chapter two of Volume I of Les Sources concerns bibliographies of bibliographies and is roughly equivalent to Winchell's section A, subsection "Bibliography." In Les Sources, eleven pages (pp. 15-25) consist of introductory material, followed by a bibliography. The introduction discusses the forms, principles, and aims of bibliographies of bibliographies. Winchell has a third of page five of her Guide given over to introductory material for the general section on bibliography, emphasizing the importance of bibliography in the library.

Malclès's section on library catalogs, Chapter five of Volume I, discusses in five pages the importance of these catalogs, how they are made, the various ways of arranging them, and the great libraries and their advantages. Winchell in a fourth of page eight stresses the usefulness of library catalogs to catalogers and reference

TABLE 2

Top Ten Countries OF ORIGIN OF BoOKS

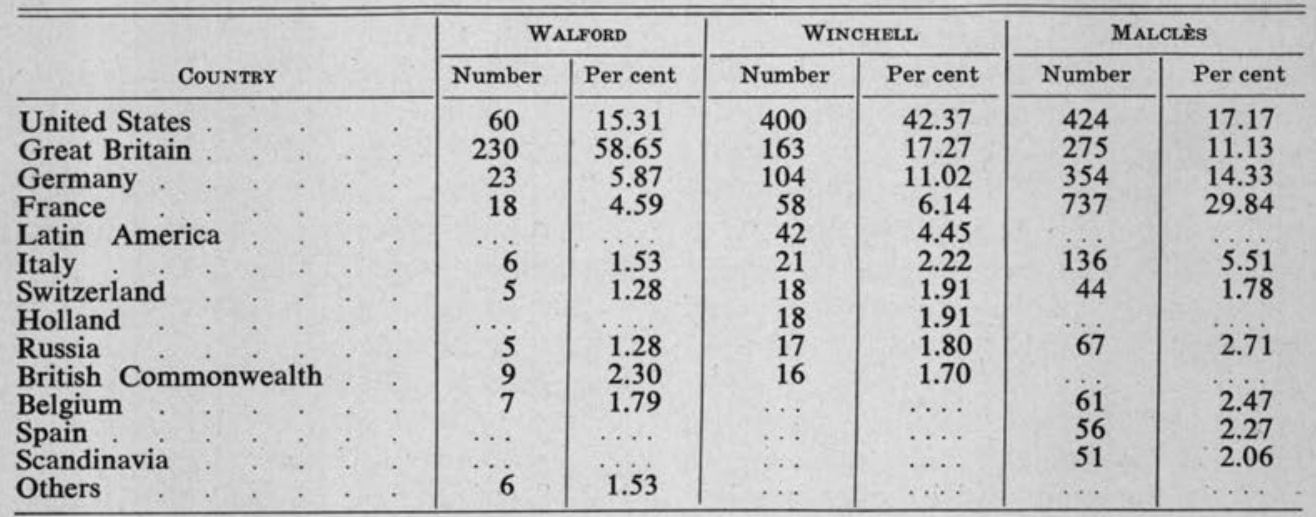


workers, and explains in one paragraph the advantages of the great national libraries.

The number of pages allotted to each general subject group in each of the guides was counted. Generalities (used here as in Walford's section "O"-thus including such materials as general, universal, and national bibliographies, encyclopedias, newspapers, government documents, etc.) received top billing in Winchell, languages and literature in Walford, and mathematics and natural sciences in Malclès. See Table 1.

A ten per cent sampling of the works in each guide was made to determine which countries produced the greatest numbers of listings. The United States, Great Britain, France, and Germany were the "big four" in all three guides. Rather unexpectedly, materials published in the United States were second highest in representation in Malclès. Indeed, in Volume III of Les Sources, more of the books cited were American than French. Russia received its best treatment in Malclès, with 2.71 per cent representation, while Winchell's percentage was 1.80 and Walford's 1.28. See Table 2 .

Which of the three guides to reference sources lists the largest percentage of truly "reference" works? To answer this question, each guide, including the first three supplements to Winchell, was checked completely. The materials cited were sorted into eight divisions as follows:
1. Reference books-dictionaries, biographies, bibliographies, encyclopedias, tables (mathematical, etc.), directories, almanacs, abstracts, field guides to animals and birds, etc.

2. Histories-books dealing with the history of a period or subject field.

3. Textbooks - textbook type works and standard works in a field, treatises, conference reports, series of papers, handbooks, etc.

4. Periodicals-serial publications appearing more frequently than once a year.

5. Reference periodicals-periodicals which are wholly of reference rather than general periodical nature (bibliographic, biographic, indexing, etc.).

6. Articles-items cited which are not in themselves books or periodicals but which appear in books or periodicals.

Reference books make up the largest portion of each guide, but the percentage of reference books in the total number of works cited differs considerably from guide to guide. In Winchell, including supplements, 7001 of the 8135 works were reference works, a percentage of 86.06 . The 2890 reference works in Walford made a lower 76.41 per cent. Although the number of reference works in Malclès was almost as large as the total of the Winchell citations, the 8123 works were only 34.55 per cent of Malclès's total. See Table 3.

TABLE 3

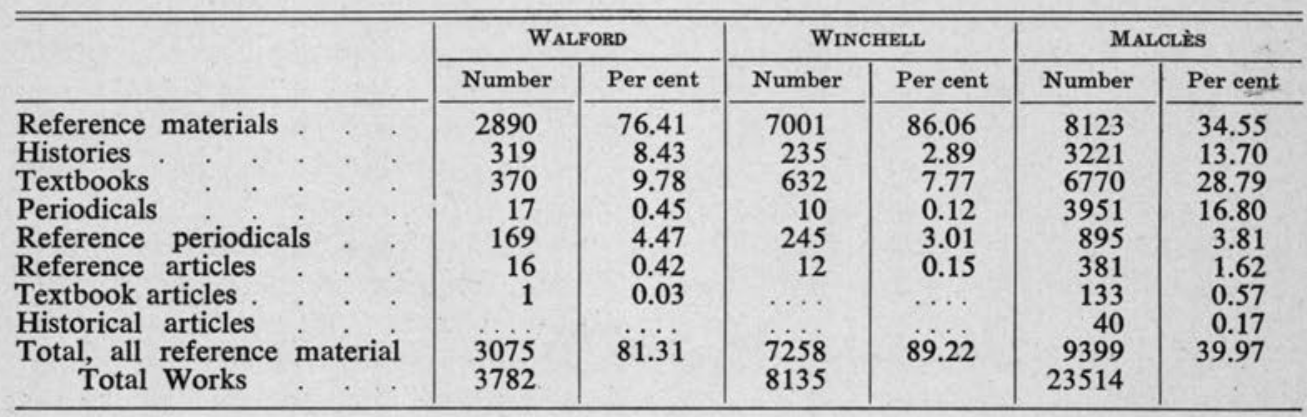


Annotations are important in a guide to reference books. According to a ten per cent sampling of each guide, annotations receive their greatest emphasis in Walford. Most of his titles-93.46 per cent-are annotated, with 7.63 lines per annotation.

Winchell's percentage of titles annotated is 72.8 , with 4.98 lines per annotation. Malclès annotates 38.11 per cent. A line of annotation in Malclès contains roughly twice the number of letters as a line in Winchell or Walford. The average in Les Sources is 1.59 lines per annotation, but for purposes of comparison, the number would be figured as 3.18 .

In order to establish a list of books annotated by all three guides, titles from four lists of reference books used in courses at the University of Minnesota graduate library school were checked against the entries in each guide. Titles common to all were then analyzed for quality of annotation.

Each of the lists covered a different general subject area. Of the ninety-one items on the bibliography list, thirty-seven were found in all three guides. In humanities, 120 of the 231 works were found in all. Eighty-three of the 216 works on the social science list and eighty-three of the 320 natural science titles were found in all.

This selected list resulted in a group having a much higher percentage of annotated titles, with a larger number of lines per annotation, than the over-all average of each book. See Table 4 .

In order to achieve some degree of objectivity in comparing the annotations of each guide, the following criteria were established and checked:

1. Dates covered by the work, where relevant (e.g., Harper's Encyclopaedia of United States History from 458 A.D. to 1912).

2. Subject of the work (e.g., Psychological Index).

3. Materials covered by the work, where relevant (e.g., books, pamphlets, periodicals, etc.).

4. Amount and kind of information given in the work (such comments as, "contains long biographical articles of authors with bibliographies of their main works," etc.).

5. Arrangement of material in work.

6. Whether or not annotation evaluates the quality of the work.

These criteria were established on the basis of what the student or potential user of a reference tool would want to know about it before obtaining it. It should be noted that in many cases the title of the work contains considerable information requiring no or only partial assistance from the annotation for clarification. For results, see Table 5 .

A subjective evaluation was made of the annotations studied and each was rated, using "average" to mean the basic minimum of information to be expected. Walford had the largest number rating above average, 199, or 66.12 per cent. Winchell had 188 , or 59.31 per cent. Malclès had 69 above average, for 21.36 per cent.

Reviewers have noted that Walford is especially strong in annotations, with Winchell a close second, while Malclès gives less attention to this area. The detailed annotation analysis bears out the strength of Walford's annotations, as does subjective evaluation. However, there are certain exceptions. Malclès occasionally offers annotations which are masterpieces of thoroughness and at other times compresses an amazing quantity of information into one or two of her double-length lines. Much better coverage of certain works is given in Malclès than in either Walford or Winchell.

In looking over annotations common to both, one receives the impression that Walford's annotations are sometimes based on those of Winchell, usually undergoing a refining process first, so that the result is more compressed than the 
TABLE 4

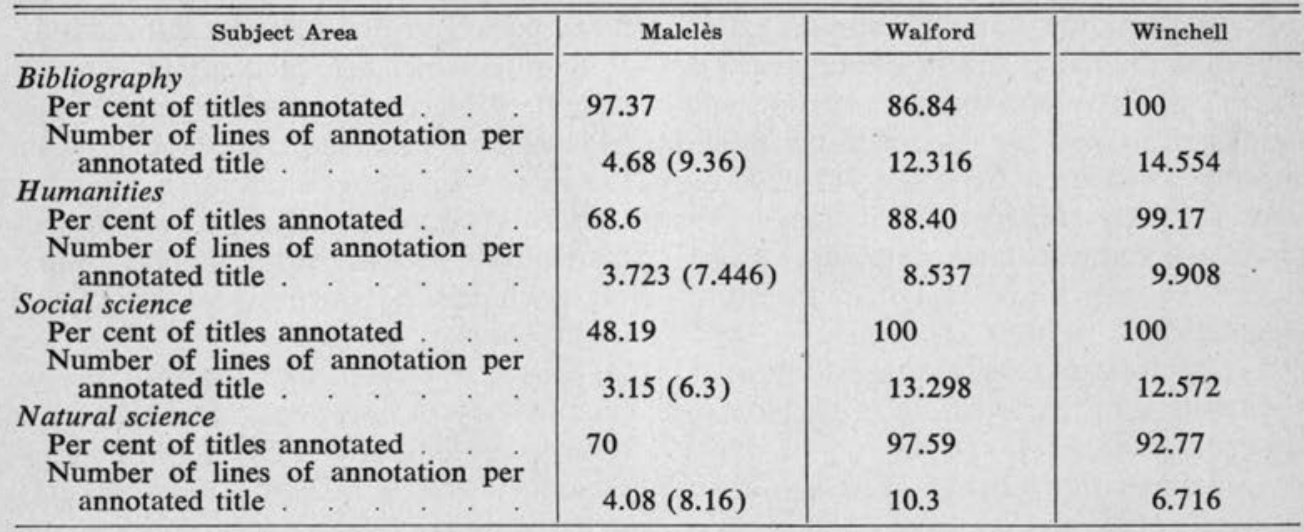

TABLE 5

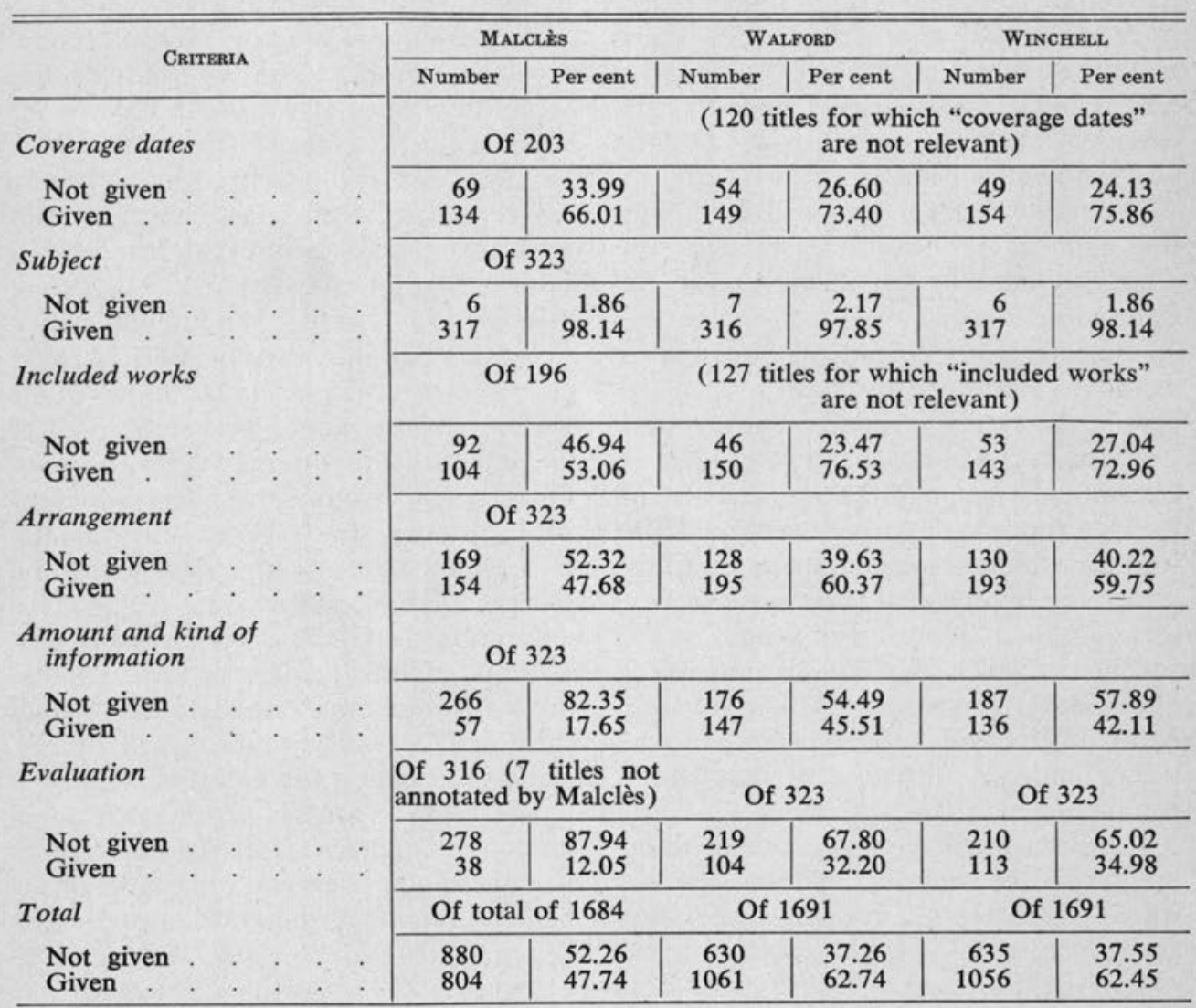


original. Both guides quote extensively from prefaces and introductions, and not always from the more illuminating portions. A reduction in the use of this type of material, except where it is especially valuable, would be a space-saver and would not detract from the value of the works. Frequent lists of inclusions or faithful reproductions of tables of contents are not always the help they may seem to be.

The following general suggestions could be made for the correction of weaknesses in each guide:

Malclès's outstanding need is an improved index, one giving title along with page number under an author's name. In Volumes I and II, the Balkan and Slavic countries should be integrated into the major subject groupings. At present, the works of these countries are listed under the country rather than under the subject as are the works of other countries. Some method of supplementation or revision for Les Sources should be developed, for the early volumes are now much out of date, and even out of print.

Walford's greatest drawback is the limited number of titles he includes. The work cannot really stand alone and should be used in connection with Winchell.

Winchell's work, and Walford's also, would be improved by more discrimination in the choice of annotation material. Compression and concision would reduce the present volume of the annotations and provide room for a larger number of listings. Consideration should be given to the possibility of replacing extensive historical material about a work with a reference to sources in which this information would be available in greater detail. Care must be used here; and material essential to the use or understanding of a work must not be eliminated in this way.

Citations might be used for full information on the extensive editorial changes which often take up so much space. And perhaps a symbol could replace "gives author, title, place, publisher, date, volumes, paging, series, prices." This comment occurs in many of the annotations. Where possible, Winchell might summarize the prefaces she loves to quote from, because the complete quotation is often too wordy for a brief annotation.

Both Walford and Winchell would benefit from an increase in the number of listings included. All three works are plagued by problems of currency.

With the present-day increase in the quantity of publications, none of these guides can fill the need for a guide to reference sources. Complete, universal bibliography is, as reviewers so often remark, a thing of the past and the most that can be attained now is a thorough bibliography of a particular subject field. It seems, therefore, that a guide to reference sources should be the key, the top of the pyramid of bibliographic works.

A guide to reference sources should reflect use by librarians, researchers, and students. It must give a broad view of the whole field of reference works to librarians, provide the beginning of a key to subject fields for the researcher, and offer good annotations to students. It must give information on both timeless and current reference works and bibliographies.

To meet all the needs of users of reference guides, a system similar to that of the Wilson indexes could be established. A guide published semi-annually with cumulations every two or three years would insure currency. Each permanent cumulation would have to be independent and complete in itself, as are the various editions of the Guide to Reference Books. It would include the best possible annotations for the most vital works. Rather than include extensive historical or editorial information for a particular title, it would refer to articles giving such information in greater detail. In addition, it would include as broad a listing of unannotated reference materials as required.

(Continued on page 31) 
literature. Just as, in the words of Joseph de Maistre, "Chaque nation est pour l'autre une postérité contemporaine," ${ }^{15}$ so can each related discipline be a discerning critic for another. Once established, criticism in science should find its own form of expression. It can then make scientific literature, as R. A. Scott-James put it for the relation of literary criticism to literature in general, "self-conscious about itself, about its own processes, its technique, its aim."16

In the February 1963 issue of The Rockefeller Institute Review, John Maddox has raised the crucial question: "Is the Literature Worth Keeping?" 17 We believe that what deserves to be called literature in science is worth keeping, but we need not look for it in the machines that may eventually assist us in recording it. A chiefly technological approach has been promoted for about twenty years

\footnotetext{
${ }^{15}$ Louis Paul Betz, Studien zur vergleichenden Literaturgeschichte der neueren Zeit (Frankfurt a. M. : Rütten \& Loening, 1902), p. 13.

${ }^{16} \mathrm{Op}$. cit., p. 14 .

17 "Is the Literature Worth Keeping?" Rockefeller Institute Review, I (1963), 9-14; an abridged version appears in Bulletin of the Atomic Scientists, XIX (November 1963), 14-16.
}

now, and yet the "crisis in scientific information" has been aggravated rather than relieved. Underlying this crisis is the lingering use of a concept of scientific literature which was new at the turn of the century. It was a misunderstanding to apply this concept directly to the bibliography of twentieth-century science by merely trying to list all current publications in a given field.

The time has come to cultivate a concern over the evolving contemporary scientific literature, and to develop adequate bibliographic methods through a scholarly approach. This need not be done in an atmosphere of crisis. By taking the longer view of the historian, the humanist, and the librarian, we can see even now that some problems of scientific information storage and retrieval seem to defy solution because they do not need one. For information that does not contribute to scientific knowledge is not worth retrieving, and the only indestructible way of storing scientific knowledge is by allowing it to become scientific literature, and by helping it to become so recognized and known.

\section{Winchell, Walford, or Malcles?}

(Continued from page 26)

Its index would be thorough and its format similar to that now used by Winchell, if this would be possible under required printing methods.

Wilson's Reader's Guide to Periodical Literature is now available in the regular edition and also in an abridged edition for small libraries. Perhaps a similar arrangement could be developed for a guide to reference sources. This could be on a three-step basis: (1) an "international" edition of broad scope for large public and university libraries; (2) a small edition primarily national in scope, for smaller public libraries; and (3) a middle edition for the medium-sized libraries.

A full-time organization would probably be necessary to handle a production of this scope. However, the gap around existing reference guides widens each year. A practical tool must be developed to fill this gap. 